\title{
Aimé Césaire, Nègre je suis et nègre je resterai
}

\section{Francesca Torchi}

\section{(2) OpenEdition}

\section{Journals}

\section{Edizione digitale}

URL: http://journals.openedition.org/studifrancesi/28237

DOI: 10.4000/studifrancesi.28237

ISSN: 2421-5856

\section{Editore}

Rosenberg \& Sellier

\section{Edizione cartacea}

Data di pubblicazione: 31 décembre 2006

Paginazione: $650-651$

ISSN: 0039-2944

\section{Notizia bibliografica digitale}

Francesca Torchi, « Aimé Césaire, Nègre je suis et nègre je resterai », Studi Francesi [Online], 150 (L | III) |

2006, online dal 30 novembre 2015, consultato il 08 novembre 2020. URL : http://

journals.openedition.org/studifrancesi/28237 ; DOI : https://doi.org/10.4000/studifrancesi.28237

\section{Questo documento è stato generato automaticamente il 8 novembre 2020.}

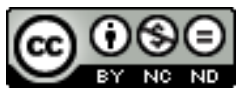

Studi Francesi è distribuita con Licenza Creative Commons Attribuzione - Non commerciale - Non opere derivate 4.0 Internazionale. 


\title{
Aimé Césaire, Nègre je suis et nègre je resterai
}

\author{
Francesca Torchi
}

\section{NOTIZIA}

AIMÉ CÉSAIRE, Nègre je suis et nègre je resterai, Entretiens avec Françoise VERGÈs, Paris, Albin Michel, 2006, pp. 149.

1 A sessant'anni dalla dipartimentalizzazione di Martinica, Guadalupa, Guyana e Réunion, in un momento in cui la Francia si interroga sulle tracce del colonialismo e della schiavitù, una nuova riflessione su Aimé Césaire assume un valore significativo. In più, il nome di Aimé Césaire compare tra i candidati per l'anno 2006 al il premio Nobel per la pace. La lunga conversazione con Françoise Vergès non solo è la testimonianza di una grande lucidità sugli eventi storici, sul passato della Martinica e sui problemi che caratterizzano il mondo contemporaneo da parte di Césaire, ma anche della grande umiltà che lo ha portato ad affermare di non avere le qualità per meritare un premio per la pace. Di domanda in domanda si delinea il profilo dell'uomo, dello scrittore, del politico e, in prospettiva, del ruolo di Césaire come figura storica. In un unico discorso, le risposte di Césaire comprendono i fatti storici che lo hanno visto parte attiva, il pensiero della Négritude e la riflessione sulla colonizzazione e sulla schiavitù insieme ai ricordi personali di una vita, come il sentimento provato al momento della partenza dalla natale Martinica o l'incontro con Léopold Sédar Senghor, la loro amicizia e le loro conversazioni. Il ritratto dell'uomo si intreccia dunque alla nascita di un pensiero, di cui viene ribadito lo stretto rapporto con l'epoca in cui nasce ma anche un carattere universale che va al di là delle critiche che gli autori martinicani delle generazioni successive gli hanno mosso. La produzione letteraria è solo uno degli aspetti della vita di quest'uomo che ha agito su più fronti in nome di uno stesso ideale. Le domande cui Césaire risponde sono di carattere ampio e le risposte riguardano soprattutto le posizioni iniziali dello scrittore, il suo rapporto con la Martinica e con la Francia, la sua attenzione per Haiti. Césaire riflette inoltre sul significato del potere politico ed espone 
il proprio concetto di umanesimo. In quest'ottica, il riferimento alle sue opere diventa un'argomentazione ulteriore per approfondire una peculiare visione del mondo e della storia.

Nègre je suis et nègre je resterai raccoglie, oltre alla lunga intervista che costituisce il cuore del volume, un'introduzione della curatrice Françoise Vergès, una postfazione critica, una cronologia e una bibliografia completa di e su Aimé Césaire. Françoise Vergès, nella postfazione, si propone di dimostrare che è possibile rileggere l'opera di Césaire alla luce delle problematiche poste dalla critica postcoloniale, ed afferma che «il est question d'insister sur une approche césaireienne de la postcolonialité, à la fois modélée par le colonialisme et échappant à son emprise» (p. 100). Nata soprattutto in ambito anglofono, la critica postcoloniale si rivela per la curatrice un «outil, un 'clignotant' rappelant la situation d'inégalité dans le rapport au savoir reconnu» (p. 78). Dopo aver tracciato i punti salienti di questo approccio, Françoise Vergès insiste sull'importanza dello studio delle strategie di rappresentazione che si riscontrano nei testi, strategie di inclusione ed esclusione che si stabiliscono fra la colonia e la metropoli ma anche tra la colonia e se stessa. Uno degli esempi più significativi di questo procedimento è, ad esempio, l'assenza dei colonizzati nei testi che si volevano universali. La prospettiva postcoloniale implica una decostruzione della lettura della storia tradizionale che è per l'autrice una modalità necessaria al fine di comprendere come si creano strategie di identificazione «raciale, ethnique, sexuelle et politique dans des contextes de contacts violents, voire de conflits, entre des systèmes d'identification placés en situation de contact mais de position inégale» (p. 83). Dopo queste premesse, il discorso attorno a Césaire si struttura attraverso lo studio delle opere, del pensiero e dell'azione dello scrittore martinicano in relazione a schiavitù e colonialismo, un'operazione di genealogia che permette di vedere i motivi della grande attualità di Aimé Césaire. 